\title{
Study on Maintenance and Utilization of Tamed Sumatran Elephants (Elephas maximus sumatranus Temminck 1847) at the Elephant Training Center in the Seblat TWA Area, Bengkulu
}

\author{
Rizwar $^{1,{ }^{*}}$ Darmi $^{1}$ C. H. Sukoco ${ }^{2}$ \\ ${ }^{1}$ Department of Biology, Faculty of Mathematics and Natural Sciences, Universitas Bengkulu, Kandang Limun, \\ Bengkulu 38112, Indonesia \\ ${ }^{2}$ Undergraduate Student, Department of Biology, Faculty of Mathematics and Natural Sciences, Universitas \\ Bengkulu, Kandang Limun, Bengkulu 38112, Indonesia \\ Corresponding author.Email: rizwar@unib.ac.id
}

\begin{abstract}
In the range of 23 years, from 1992 to 2015, there has been a drastic decrease in the number of individual tamed Sumatran elephants (Elephas maximus sumatranus Temminck 1847) at the Seblat Elephant Training Center (PLG) from 40 individuals to 18 individuals. Decreasing the size of the tamed elephant population is suspected to be inappropriate elephant maintenance at PLG, disease, old age and malnutrition. Good governance in the maintenance and utilization of tamed elephants at PLG is thought to be able to increase the life span of elephants and their reproductive capacity. This study aims to examine the management of PLG, especially in the maintenance and utization of tamed elephants conducted by BKSDA, Bengkulu Province. The study was conducted by direct survey method to PLG Seblat and interviewing as well as searching various relevant literatures. The parameters observed refer to the minimum standard reference for handling elephants in captivity. The results of the study found that the maintenance and utilization of the tamed elephants at PLG were only partially fulfilling the minimum standard of management of the guided elephants such as training, grazing, trekking and patrolling. While the form of maintenance that is still below the standard that needs to be improved is related to the handling of elephant health and mitigation of tamed elephant conflict with communities around the PLG
\end{abstract}

Keywords: Sumatran Elephant, TWA and Seblat PLG, Maintenance and Utilization of tamed Elephants

\section{INTRODUCTION}

Seblat Nature Tourism Park (called TWA Seblat), aside from being a habitat for endangered wildlife conservation, is also used as a place for wild Elephant Training Centers (called PLG) to become tame elephants. TWA was established based on the proposal of the Head of regional office of the Forestry Ministry and the recommendation of the Governor of Bengkulu Province Number: 522/7754 / B / 1992. The Minister of Forestry of the Republic of Indonesia confirmed the existence of TWA Seblat covering an area of \pm 7.737 ha, through Decree No. 643 / Kpts-II / 2011 [1].
The sustainability of the TWA Seblat forest is currently under threat because the forest land contains relatively large coal reserves which have become the target of investors. In addition, the TWA area is also surrounded by oil palm plantations from large companies, transmigration areas and local communities who are hungry for land [2]. This situation thought to have an impact on the lives of elephant populations and other wildlife in it. Wild elephant populations in the Seblat forest area to split into two sub-populations. The first sub-population is in the downstream Air Senaba-Air Rami trapped in situ in the Seblat TWA area due to the presence of a barrier in the form of a large plantation area of PT. 
Alno and the second sub-population inhabit the upstream Air Seblat and Upstream Air Rami forests outside the TWA Seblat area [3]. Trapped conditions in the TWA area have caused elephant populations to often enter and damage the plantation and agricultural crops of the communities around TWA. The Elephant Training Center (PLG) was built aimed at capturing wild elephants that are often in conflict with humans, then tamed through training and maintenance as well as being used as a tourist attraction, repelling wild elephants that enter community land and forest patrols [3-5].

In 1992, the Seblat forest area which included TWA and its surroundings, had around 375 - 390 individuals of wild elephants and domesticated (scouted) elephants in PLG as many as 40 individuals [6]. When this study was conducted, based on Bengkulu BKSDA information, the number of remaining wild elephants trapped in the Seblat TWA area was estimated to be around 40-50 individuals and 18 tamed elephants. Thus in 23 years, there has been a drastic decrease in the number of Sumatran elephants in both the wild elephant population and the tamed elephant.

The decline in the population of wild elephants in the Seblat TWA area is due to reduced forest habitat area due to illegal logging and poaching [5], while the decline in the population of tamed elephants in PLG is thought to be due to poor management, disease, old age and malnutrition. Good governance in the maintenance and utilization of fostered elephants in Captivity can increase the chances of elephant life and reproductive capacity [7]. This study aims to examine the management of PLG, especially in the utilization and maintenance of fostered elephants conducted by BKSDA Bengkulu Province.

\section{MATERIALS AND METHODS}

This research was conducted for one month from October to December 2016, with an effective observation period for 30 days starting at 08.00-16.00 WIB at the Elephant Training Center (PLG) Seblat, Bengkulu Utara Regency.

The study was conducted by direct survey method (direct survey) in the field and interviewing elephant handlers (mahout) as well as by collecting supporting data from various relevant literature. The parameters observed refer to the guide for management of tamed elephants from [5-6], [9-10] which include:

1. Elephant health, which is in the form of preventive (preventative) and curative (treatment) activities which include the timing of periodic vaccines. In addition, also observed ways to care for nails, weight weighing, and height measurements.

2. Elephant training, what things are taught in training elephants and what training methods are used.

3. Grazing, is elephant grazing activities carried out by mahout directing elephants to bathe and eat in the space provided.

4. Trekking is a mahout riding an elephant by walking along the edge of the forest with a number of tourists. Any activities carried out by elephants during trekking are recorded.

5. Patrols namely mahouts bring elephants into the forest and oversee the Seblat TWA forest area. The purpose of the patrol is recorded.

6. Conflict mitigation, where TWA Seblat tamed elephants in conflict with local communities often occur. Any mitigation efforts undertaken by PLG officers to deal with the conflict of fostered elephants are also noted.

Data on utilization and maintenance of tamed elephants in PLG Seblat, Regency of North Bengkulu in Bengkulu Province was analyzed qualitatively and described descriptively.

\section{RESULTS AND DISCUSSION}

In general, the care and utilization of Sumatran elephants in Seblat PLG have relatively met the standards based on the guidance of the management of tamed elephants from [8-11] except in the curative and conflict mitigation activities which have so far not met the standards yet (Table 1).

From field observations, individual elephants fostered in the Seblat PLG captivity are very susceptible to various diseases such as diarrhea, tetanus, tuberculosis (TB), ectoparasites such as lice (mites) and bloodsucking insects, endoparasites such as liver worms (Fasciola), mine or bracelet worms and others. This is because the types of feed plants that are given are less varied, contact with humans infected with tuberculosis both inside and outside the PLG is very intense, the feed provided is not clean so it is likely to have been contaminated with worm eggs and fostered elephants are often used for herding, trekking and patrol so the chances of injury and infection are quite high.

From the study of [12] found that the most common ectoparasites attacking PLG-tamed elephants were blood-sucking Diptera of Culicoides 
fulvusin while endoparasites were types of worms Fasciola, Toxocara and Oxyuris. Parasitosis such as helminthiasis (nematods) is one of the most common diseases in elephant breeding. Fasciola liver worms and nematods are known to be a cause of death for elephants fostered by Aek Nauli Elephant Conservation Camp, North Sumatra and Way Kambas PLG, Lampung [11], [13-14] and several elephant individuals in PLG Seblat.
The health of elephants in captivity should have a hospital building, clinic or ward, laboratory room, quarantine room, isolation room and adequate veterinary or medical staff. The unavailability of complete facilities is the main factor causing diseased elephants to be handled properly. Inadequate and fast handling of curatives, inadequate medical devices and medicines are the determining factors for the death of tamed elephants in Captivity [15-16].

Table 1. Management of tamed Sumatran elephants at PLG Seblat, Bengkulu

\begin{tabular}{|c|c|c|c|}
\hline No & Management Type & $\begin{array}{c}\text { Standard based on BKSDA }(2004) * \text {, Sarma \& } \\
\text { Wardana }(2004) * * \text { and Syamsuardi et al. }(2001) \\
* * * .\end{array}$ & Observation results \\
\hline \multirow[t]{3}{*}{1.} & Elephant Health** & & \\
\hline & -Preventive action & $\begin{array}{l}\text { Giving worm medicines periodically, cleaning nail, } \\
\text { weighing body weight }\end{array}$ & Meet standard \\
\hline & -Curative action & $\begin{array}{l}\text { Giving medicines directly if elephants get wounds, } \\
\text { eye iritation, stock of medicines available, Clinic } \\
\text { facilities such as operation room and caring room } \\
\text { available, medic team stay permanently in PLG }\end{array}$ & No standard \\
\hline 2. & $\begin{array}{l}\text { Elephant Training* } \\
\text { - Basic } \\
\text { - Advance } 1 \\
\text { - Advance } 2\end{array}$ & $\begin{array}{l}\text { Giving training types based on specialization of } \\
\text { elephants (for catching, riding, pulling up, attraction) }\end{array}$ & Meet standard \\
\hline 3. & Ranching*** & $\begin{array}{l}\text { Pastoring elephants into forest during } 4 \text { hours for } \\
\text { finding additional feed }\end{array}$ & Meet standard \\
\hline 4. & Trekking* & $\begin{array}{l}\text { Riding elephant to bring tourists seeing flora and } \\
\text { fauna in TWA Seblat. }\end{array}$ & Meet standard \\
\hline 5. & Patrols * & $\begin{array}{l}\text { Officials ride elephants go into Seblat TWA forest to } \\
\text { drive out wild elephants in private and local } \\
\text { community ( } 2 \mathrm{x} / \text { month) }\end{array}$ & Meet standard \\
\hline 7. & Conflict mitigation $* *$ & $\begin{array}{l}\text { Making special barrier between PLG site and local } \\
\text { community lands. }\end{array}$ & No standard \\
\hline
\end{tabular}

Death of Seblat PLG elephants is also caused by other factors. Based on interviews from mahout (handler), there are two elephants that died from bloating and old age while others were because of poaching by poisoning.

In Seblat PLG, the medical team did not stay in PLG so the treatment of sick elephants was less than optimum and was often only handled by each handler. Besides the stock of medicines is also relatively limited, causing less than optimal treatment of elephants. Every captive facility must have an adequate stock of medicines such as Iodine Tincture (wound medicine), Anthelmentic (worm medicine), antipyretic drugs (drugs to reduce body temperature), analgesic drugs (painkillers), respiration and urinary, vitamins, skin ointment, eye ointment, fly repellent spray (insecticide) and gusanex (wound spray) and others [9-10].

The training process of PLG Seblat-tamed elephants uses certain techniques and stages. The training aims to form an elephant with different specializations in accordance with its designation as catching elephants,

riding elephants, pulling elephants, and attraction elephants [5,17]. The method used to train tamed elephants is shown in Table 2. There are eight types of training for capturing elephants, fifteen riding elephants, eight kinds of drag elephants and twentyseven attraction elephants. Of the four elephant specialties, elephant attraction is the most widely performed type of training. This is due to the attraction elephants undergoing every training method starting from basic training, first advanced training and second advanced training, each stage is carried out because the attraction elephant is the elephant that is closest to humans and does activities around humans so that the attraction elephant must be really tame and mastering the training stage.

Riding elephants do fifteen types of training because the riding elephant is one of the elephants that has an important role, especially in the Seblat PLG. The riding elephant is also one of the elephants 
closest to humans, including those not a handler and the elephant riding through three types of training namely basic, first advanced and second advanced training [5]. The difference with elephant attractions is that elephant riding does not learn everything at the stage of advanced training.

The elephants that undergo the least training process are captured elephants and drag elephants. Capture elephants and tug elephants are elephants that rarely interact with humans except mahout and are placed in the forest. Catching elephants and pulling elephants only go through two stages of training namely basic training and advanced training [17]. The grazing of elephants in PLG Seblat is carried out by mahout of each elephant which starts at 08.00 WIB - 16.00 WIB. Elephants are brought on rides by each handler into the forest, this is done to meet the natural feed of the elephant is also important to reduce the cost of additional food.

Table 2. Kinds of Training Given based on Elephant Specialization

\begin{tabular}{|c|c|c|c|c|c|}
\hline \multirow{2}{*}{ No } & \multirow{2}{*}{ Types of Training } & \multicolumn{4}{|c|}{ Spesialization for } \\
\hline & & Catching & Riding & Pulling & Attraction \\
\hline \multicolumn{6}{|c|}{ Basic Training } \\
\hline 1 & Lifting leg on Runk & $\sqrt{ }$ & $\sqrt{ }$ & $\sqrt{ }$ & $\sqrt{ }$ \\
\hline 2 & Back occupied & $\sqrt{ }$ & $\sqrt{ }$ & $\sqrt{ }$ & $\sqrt{ }$ \\
\hline 3 & Neck occupied & $\sqrt{ }$ & $\sqrt{ }$ & $\sqrt{ }$ & $\sqrt{ }$ \\
\hline 4 & Driven Training & $\sqrt{ }$ & $\sqrt{ }$ & $\sqrt{ }$ & $\sqrt{ }$ \\
\hline 5 & Following other elephants & $\sqrt{ }$ & $\sqrt{ }$ & $\sqrt{ }$ & $\sqrt{ }$ \\
\hline \multicolumn{6}{|c|}{ Advanved Training (1) } \\
\hline 6 & Taking something with trunk & $\sqrt{ }$ & $\sqrt{ }$ & $\sqrt{ }$ & $\sqrt{ }$ \\
\hline 7 & Sitting & $\sqrt{ }$ & $\sqrt{ }$ & $\sqrt{ }$ & $\sqrt{ }$ \\
\hline 8 & Lifting leg where mahout rises and downs & $\sqrt{ }$ & $\sqrt{ }$ & $\sqrt{ }$ & $\sqrt{ }$ \\
\hline \multicolumn{6}{|c|}{ Advanced Training (2) } \\
\hline 9 & Back mounted other people & - & $\sqrt{ }$ & - & $\sqrt{ }$ \\
\hline 10 & Sitting for long time & - & $\sqrt{ }$ & - & $\sqrt{ }$ \\
\hline 11 & throwing tree bark away by trunk & - & $\sqrt{ }$ & - & $\sqrt{ }$ \\
\hline 12 & Taking bathe by itself & - & $\sqrt{ }$ & - & $\sqrt{ }$ \\
\hline 13 & Knocking down tree bark & - & $\sqrt{ }$ & - & $\sqrt{ }$ \\
\hline 14 & Running fast & - & $\sqrt{ }$ & - & $\sqrt{ }$ \\
\hline 15 & Pulling wood beam up & - & $\sqrt{ }$ & - & $\sqrt{ }$ \\
\hline 16 & Respectful practice & - & - & - & $\sqrt{ }$ \\
\hline 17 & Parade training & - & - & - & $\sqrt{ }$ \\
\hline 18 & Probocis handle & - & - & - & $\sqrt{ }$ \\
\hline 19 & Sitting on the floor & - & - & - & $\sqrt{ }$ \\
\hline 20 & Sitting on milestone & - & - & - & $\sqrt{ }$ \\
\hline 21 & Standing up on milestone & - & - & - & $\sqrt{ }$ \\
\hline 22 & Standing up with 2 hind legs on floor & - & - & - & $\sqrt{ }$ \\
\hline 23 & Standing up with 2 legs on milestone & - & - & - & $\sqrt{ }$ \\
\hline 25 & Photo model training & - & - & - & $\sqrt{ }$ \\
\hline 26 & Kicking ball & - & - & - & $\sqrt{ }$ \\
\hline 27 & Dancing & - & - & - & $\sqrt{ }$ \\
\hline 28 & Bringing person with trunk & - & - & - & $\sqrt{ }$ \\
\hline 29 & Pretending to sleep & - & - & - & $\sqrt{ }$ \\
\hline 30 & Taking goods & - & - & - & $\sqrt{ }$ \\
\hline 31 & Hanging flower & - & - & - & $\sqrt{ }$ \\
\hline 32 & Stepping over people & - & - & - & $\sqrt{ }$ \\
\hline & Total & 8 & 15 & 8 & 27 \\
\hline
\end{tabular}

When being herded, the condition of the elephant's feet is handcuffed so that the elephant does not run away from the community plantations when the elephant is abandoned. After the afternoon the elephant was picked up again by the handler and then immediately taken to the river to meet the drinking water needs of the elephant, after that the elephant was immediately instructed to bring additional feed in the form of palm oil fronds and tied at an elephant tethering site around the camp.
Pastoral activity in the Seblat TWA PLG has met the criteria because according to [10], good grazing of elephants is done after elephants are bathed and grazing must be done with a minimum period of two hours with good availability of natural food. The tamed elephants in WKNP Lampung are not always in cages or moorings, but elephants are released to enter the forest with the aim of finding natural food sources and wallowing sites [14]. Herding is also 
intended to allow elephants to freely feed according to their preferences.

Trekking activities at Seblat PLG are tour packages for visitors who want to ride elephants into the forest to observe wild flora and fauna in TWA Seblat. In addition, visitors can bathe, provide food and take pictures directly with elephants. Trekking activities are conducted were visitors and mahout as drivers. The trekking method in Seblat PLG is not different from that applied in the TN Tesso Nilo PLG, Riau [18]. Trekking activities in Seblat PLG have met the criteria applied by Bengkulu BKSDA, where trekking packages are implemented by providing tour packages for visitors and are charged based on the package chosen.

The Seblat TWA area still has many wild elephants that often damage community plantations and private plantations, therefore BKSDA conducts routine activities namely Patrol. Patrol activities in the TWA Seblat PLG are carried out twice a month, namely at the beginning of the month and at the end of the month. This patrol activity was carried out for ten days and consisted of three teams. The elephants that are brought must be in a healthy condition and the handlers must carry medicine equipment, machetes and ambiguous. Patrol aims to drive out groups of wild elephants that are approaching the plantation area. In addition, the patrol also aims to count the number of wild elephant groups that remain by looking at traces and faeces, driving out forest encroachers, and rescuing wildlife protected from snares or hooks installed by the community [5].

As a comparison, patrol activities with tamed elephants in the Tesso Nilo Patrol National Park are also carried out routinely on Tuesday and Saturday patrol at 08:00 - 17:00 WIB. The handler is equipped with equipment to drive / herd elephants, which are paralon cannons and spears. In patrols the presence of wild elephants includes sound, direction of footprints, feces, wrestling, broken or fallen trees which are passed by wild elephants. If the direction of the movement of wild elephants to the village or population settlement, then the trail continues to be traced until found wild elephants both single and in groups that will be driven out [18].

Patrol activities in Seblat PLG have fulfilled the procedures of BKSDA where patrols are carried out during the day by carrying healthy elephants, in a state of non-heat and complete equipment, namely: ambiguous, carbide cannon, machetes, matches, location maps, GPS, medicines (P3K), stationery, and metre $[5,10]$.
Conflicts between the tamed elephants and humans often occur because the location of the PLG is adjacent to the location of the plantation and community settlements. The parties only bound the fostered elephants with chains at the moorings.

The absence of barriers in the form of concrete / electric wire fence or hedge barbed and sharpsmelling which is not preferred by elephants. Conflicts occur when tamed elephants are released semi-wild to search for food in the TWA forest and at moorings. This effort is considered not optimal to prevent the entry of elephants into community plantations, this is evidenced by observations in the field, that there is one elephant that entered the community plantations and damaged crops. This happened because the chains of the elephant chains broke and the elephants crossed the river to get to the land. After that the elephants were herded back to PLG by mahout when there was a report by the local community.

The management of conflict mitigation of tamed elephants with humans around the Seblat PLG is different from the Tesso Nilo PLG, where in this PLG, a fence is built to prevent the tamed elephants from entering the community plantations. The barrier is made in the form of a fence of ropes smeared with chili and tobacco. While electric fences, smokeproducing devices, bonfires / kerosene lamps around the garden, sound traps using fireworks or drums are often used to drive wild elephants [5,18].

According to the Elephant Conflict Reduction or Mitigation Protocol $[19,20]$ to overcome conflicts between elephants and humans there are several ways to do that are to make physical barriers in the form of sturdy fences, drive away elephants directly, foster habitat around the camp and not tether elephants in areas that are too close to community plantations. Thus, the management of Sumatran elephant conflict mitigation under the guidance of PLG Seblat and the community is still not going well because it does not meet the established standards and criteria.

\section{CONCLUSION}

From the results of research on studies in the maintenance and utilization of Sumatran elephants fostered in the Seblat PLG, North Bengkulu it can be concluded:

Maintenance and utilization of fostered elephant populations in the TWA Seblat PLG such as disease prevention, training, grazing, trekking and patrols have met management standards based on Sumatran elephant management guidelines except for curative 
treatment of sick elephants and mitigation of conflicts between fostered elephants and communities around the Seblat PLG.

Seblat PLG elephant mortality factor is caused by endoparasites, poisoning and hunting, lack of curative treatment facilities for surgery and a lack of medicines.

\section{REFERENCES}

[1] BKSDA, Regional Profile of Elephant Training Center, TWA Seblat. Bengkulu Province, 2013.

[2] F. Sitompul, Ecology and Conservation of Sumatran Elephants (Elephas maximus sumatranus) in Sumatra, Indonesia.University of Massachussetts Amhaerst, ScholarWorks@Umass_Amherst. https://scholarworks.umass.edu/open_access_dis sertation, 2011.

[3] Rizwar, Darmi, Zulfian, Population Density and Condition of Elephant Habitat (Elephas maximus sumatranus Temmick, 1847) in Forest Fragmentation in the Kerinci Sebelat National Park Area, North Bengkulu Regency. Report of Integrated Conservation Development Project- KEHATI, Jakarta, 2002.

[4] E.L. Rustiati, Priyambodo, Y. Yulianti, E.A. Srihanto, D.N. Pratiwi, E. Virnarenata, T. Novianasari, E.D. Krismuniarti, E. Saswiyanti, The Essential Contribution of Captive Sumatran Elephant in Elephant Training Center, Way Kambas National Park for Wildlife Genetics Conservation, Biovalentia: Biological Research Journal 6 (1) (2020) 2477-1392.

[5] D. Olson, Support of Conservation Response Unit (CRU) at the Seblat EEC in Bengkulu Province, Final Report 98210-5-G177 Azle, Texas 76098. International Elephant Foundation (IEF), 2006.

[6] BKSDA, Inventory of Elephant Human Conflict around PLG Seblat, Bengkulu Province, 2012.

[7] J. Veasey, Concepts in the care and welfare of captive elephants, Int. Zoo Yb 40. (2006) 63-79.

[8] BKSDA, Technical Guidelines for Elephant Management. Seblat Elephant Training Center. Bengkulu Province, 2004.

[9] K. Sarma, W. Wardana, Medical Evaluation, and Health Care and Management Protocols of Captive Elephants in Riau, Sumatra,
Indonesia. Technical Report. WWF Indonesia, Areas Tesso Nilo Program. Jakarta, Indonesia, 2004.

[10] Syamsuardi, W. Sukmantoro, Muslino, Nukman, N. Fadhli, A. Purwoko, Riyadin, E. Heri, J. Prawoto, Standard operational procedures for the Elephant Flying Squad in mitigating humanelephant conflict. Riau Province, 2010.

[11] J. Melia, A. Sutriana, M. Hanafiah, M. Wahyu, A. Lubis, A. Fakhrurrozi, T.A. Maulana, M.N. Sari, Health Status Examination of Sumatran Elephant (Elephas maximus sumatranus) Using Ultrasonography, Cortisol Analysis and Parasite Identification in Aek Nauli Elephant Conservation Camp (ANECC) and Tangkahan Conservation Response Unit (CRU), North Sumatra, E3S Web of Conferences 151,01053 (2020).

https://doi.org/10.1051/e3sconf/2020151010531

[12] Rizwar, Darmi, D. Wansir, D. Mardianti, Ecto And Endoparasites on Sumatra Elephant Population at Seblat Elephant Training Center, Bengkulu Province, Indonesia, J. Adv. Zool. 38(2) (2017) 178-185

[13] D. Miller, B. Jackson, H.S. Riddle, C. Stremme, D. Schmitt, T. Miller, Elephant (Elephas maximus) Health and Management in Asia: Variations in Veterinary Perspectives, Hindawi Publishing Corporation Veterinary Medicine International, Volume 2015, Article ID 614690, 19pages,

(2015).

http://dx.doi.org/10.1155/2015/61469

[14] Muryani, Worms in Sumatran Rhinoceros Stool (Dicerhinus sumatranensis) and Sumatran Elephant (Elephas maximus sumatranus) in Way Kambas National Park Lampung (semi-insitu). Thesis. Faculty of Veterinary Medicine. IPB. Bogor. Not published, 2008.

[15] PKBSI (Association of Zoos throughout Indonesia), Management of Animal Parks in Indonesia, Jakarta, 2000.

[16] P. Bansiddhi, J. L. Brown, C. Thitaram, Welfare Assessment and Activities of Captive Elephants in Thailand, Animals 10 (919) (2020). doi:10.3390/ani10060919.

[17] S. Varma, P.A. Reddy, S.R. Sujata, S. Ganguly, R. Hasbhavi, An investigation into the Population Status, Management and Welfare Significance of Captive Elephants of Karnataka. 
Elephants in Captivity-CUPA/ANCF Technical Report 3a, 2011.

[18] I. Fakhrozi, R.R.A.P. Sari, R. Ma'mur, Betriaroza, H.T.A. Aksomo, Utilization of Assisted Elephants in Overcoming Human and Elephant Conflicts in Sumatra (Elephas maximus sumatranus Temminck, 1847) in Tesso Nilo National Park. Thesis. Faculty of Forestry. IPB. Bogor. Not published, 2007.

[19] WWF, Sumatran Elephant Conflict Reduction Protocol in Riau. Balai KSDA Riau, (2006).

[20] V. Vanitha, K. Thiyagesan, N. Baskaran, Social Life of Captive Asian Elephants (Elephas maximus) in Southern India: Implications for Elephant Welfare. Journal of Applied Animal Welfare Science 14 (2011) 42-58. DOI: https://doi.org/10.1080/10888705.2011.527603 